\title{
Intravenous ivabradine versus placebo in patients with low cardiac output syndrome treated by dobutamine after elective coronary artery bypass surgery: a phase 2 exploratory randomized controlled trial
}

Lee S. Nguyen ${ }^{1}$, Pierre Squara ${ }^{1}$, Julien Amour ${ }^{2}$, Daniel Carbognani ${ }^{3}$, Kamel Bouabdallah $^{3}$, Stéphane Thierry ${ }^{4}$, Caroline Apert-Verneuil ${ }^{5}$, Aurélie Moyne ${ }^{5}$ and Bernard Cholley ${ }^{6^{*}}$

\begin{abstract}
Background: Low cardiac output syndrome (LCOS) is a severe condition which can occur after cardiac surgery, especially among patients with pre-existing left ventricular dysfunction. Dobutamine, its first-line treatment, is associated with sinus tachycardia. This study aims to assess the ability of intravenous ivabradine to decrease sinus tachycardia associated with dobutamine infused for LCOS after coronary artery bypass graft (CABG) surgery.

Methods: In a phase 2, multi-center, single-blind, randomized controlled trial, patients with left ventricular ejection fraction below 40\% presenting sinus tachycardia of at least 100 beats per minute (bpm) following dobutamine infusion for LCOS after CABG surgery received either intravenous ivabradine or placebo (three ivabradine for one placebo). Treatment lasted until dobutamine weaning or up to $48 \mathrm{~h}$. The primary endpoint was the proportion of patients achieving a heart rate (HR) in the 80 - to $90-b p m$ range. Secondary endpoints were invasive and non-invasive hemodynamic parameters and arrhythmia events.

Results: Nineteen patients were included. More patients reached the primary endpoint in the ivabradine than in the placebo group (13 (93\%) versus $2(40 \%) ; P=0.04)$. Median times to reach target HR were $1.0 \mathrm{~h}$ in the ivabradine group and $5.7 \mathrm{~h}$ in the placebo group. Ivabradine decreased HR (112 to $86 \mathrm{bpm}, P<0.001)$ while increasing cardiac index $(P=0.02)$, stroke volume $(P<0.001)$, and systolic blood pressure $(P=0.03)$. In the placebo group, these parameters remained unchanged from baseline. In the ivabradine group, five patients (36\%) developed atrial fibrillation (AF) and one (7\%) was discontinued for sustained AF; two (14\%) were discontinued for bradycardia.
\end{abstract}

Conclusion: Intravenous ivabradine achieved effective and rapid correction of sinus tachycardia in patients who received dobutamine for LCOS after CABG surgery. Simultaneously, stroke volume and systolic blood pressure increased, suggesting a beneficial effect of this treatment on tissue perfusion.

Trial registration: European Clinical Trials Database: EudraCT 2009-018175-14. Registered February 2, 2010.

Keywords: Cardiac surgery, Low cardiac output syndrome, Cardiogenic shock, Postoperative atrial fibrillation, Coronary artery bypass graft, Systolic heart failure, Dobutamine, Sinus tachycardia

\footnotetext{
* Correspondence: bernard.cholley@aphp.fr

${ }^{6}$ Anesthesiology and Critical Care Medicine Department, Hôpital Européen Georges Pompidou, AP-HP, and Université Paris Descartes-Sorbonne Paris Cité, Paris, France

Full list of author information is available at the end of the article
}

(c) The Author(s). 2018 Open Access This article is distributed under the terms of the Creative Commons Attribution 4.0 International License (http://creativecommons.org/licenses/by/4.0/), which permits unrestricted use, distribution, and reproduction in any medium, provided you give appropriate credit to the original author(s) and the source, provide a link to the Creative Commons license, and indicate if changes were made. The Creative Commons Public Domain Dedication waiver (http://creativecommons.org/publicdomain/zero/1.0/) applies to the data made available in this article, unless otherwise stated. 


\section{Background}

The low cardiac output syndrome (LCOS) is an acute circulatory disorder that may occur in $2 \%$ to $10 \%$ of patients after cardiac surgery [1-4]. When pre-operative left ventricular ejection fraction (LVEF) is altered, the prevalence of LCOS increases up to 20\% [2]. In patients with coronary artery disease, the LCOS further impairs their ability to satisfy the myocardial demand in oxygen after coronary artery bypass graft (CABG) and is associated with a very high mortality rate [5]. The therapeutic management of LCOS involves dobutamine, an adrenoceptor agonist, which, having stronger beta- than alphaadrenergic effects and resulting in a decreased afterload, is considered the inotrope of choice [6]. However, dobutamine also has a strong chronotropic effect that may compromise the expected hemodynamic improvement for two main reasons. First, the tachycardia decreases left ventricular filling time and may reduce stroke volume (SV) despite the improvement in ejection force [7]. Thus, as the increase in heart rate (HR) is dose-dependent, dobutamine global effect on cardiac output $(\mathrm{CO})$ is often limited by the inherent tachycardia [8, 9]. Second, tachycardia is responsible for an increase in myocardial oxygen consumption that may aggravate myocardial oxygen imbalance [10]. These phenomena may also explain, in part, why dobutamine has been found as an independent risk factor for mortality after cardiac surgery in several studies $[11,12]$.

Ivabradine is a therapeutic agent that inhibits the sinus node $\mathrm{I}_{\mathrm{f}}$ channel, which regulates the diastolic depolarization slope, therefore inducing a decrease in HR without affecting the conduction times (atrioventricular and intraventricular) or ventricular repolarization [13-16]. As a consequence, it may lower the HR while not affecting the ventricular ejection force. In addition, the increased time for ventricular relaxation and filling may improve SV, a feature of particular importance in patients presenting with reduced ejection fraction $[17,18]$. Several case reports and controlled studies have shown that oral ivabradine administered in patients with LCOS decreased HR, improved global hemodynamics, and facilitated the weaning from dobutamine [19-23]. Moreover, the effects of the intravenous (i.v.) form of ivabradine have been documented in clinically stable patients presenting with systolic heart failure. In this population, ivabradine effectively decreased HR and increased SV along with left ventricular stroke work [24]. This study was designed to assess the hemodynamic effects of i.v. ivabradine in patients with LCOS treated with dobutamine after elective CABG.

\section{Methods}

\section{Study design}

This study was a phase II, multi-center, single-blind (sponsor not blinded) randomized placebo-controlled exploratory trial investigating the ability of i.v. ivabradine to control tachycardia in cardiac surgical patients whose LCOS was treated with dobutamine following elective CABG. Two university hospitals and three university-affiliated centers participated in the study, which was approved by ethics committees at these institutions. The trial (EudraCT: 2009-018175-14) was conducted in accordance with the principles of the Declaration of Helsinki, Good Clinical Practice guidelines, and local and national regulations. Written informed consent was obtained from all patients before any study-related procedures were performed.

The authors collected and interpreted data, drafted the manuscript, and made the decision to submit the manuscript for publication. Servier laboratories (Suresnes, France) sponsored the study and provided statistical support.

\section{Study participants}

Patients were eligible if they were between the ages of 18 and 80 years and had a planned elective isolated CABG surgery with cardiopulmonary bypass $(\mathrm{CPB})$, normal sinus rhythm, and a pre-operative echocardiographic LVEF between $20 \%$ and $40 \%$. Patients were excluded if they presented any contraindication to ivabradine or severe comorbidities. All patients were monitored with a pulmonary artery catheter (PAC CCO, Edwards Lifesciences, Irvine, CA, USA), allowing investigators to measure $\mathrm{CO}$ and venous oxygen saturation of hemoglobin $\left(\mathrm{SvO}_{2}\right)$ continuously. Patients were included if they presented an LCOS requiring dobutamine during the post-operative period. LCOS was defined by a cardiac index (CI) of less than $2.2 \mathrm{~L} \cdot \mathrm{min}^{-1} . \mathrm{m}^{-2}$ despite fluid resuscitation (guided according to CI response) and normothermia $\left(36.5 \pm 0.5{ }^{\circ} \mathrm{C}\right)$. The patients were subsequently randomly assigned in the study only if they developed a tachycardia with an HR of more than 100 beats per minute (bpm) in sinus rhythm.

\section{Randomization and treatment assignment}

Patients were randomly assigned in a 3:1 ratio by using a computer-generated list to either ivabradine or matched placebo. Treatments were given as a fast infusion of $10 \mathrm{mg}$ over $10 \mathrm{~min}$, followed by a continuous slow infusion of $10 \mathrm{mg}$ over $24 \mathrm{~h}$. The slow infusion could be renewed for up to $48 \mathrm{~h}$ if the interruption criteria were not met. Treatment was interrupted as soon as the physician initiated the decrease in dobutamine infusion rate or in case of an adverse event.

Patients and physicians were blinded to the study treatment. An independent sponsor staff was aware of allocation groups in order to analyze the data and monitor adverse events.

At any time, dobutamine could be up-titrated according to the patient's need (i.e., persistent LCOS) and epinephrine or norepinephrine could be administered in addition to dobutamine if deemed required by the physician in charge. 


\section{Endpoints and criteria of judgment}

The primary endpoint was the number and percentage of patients in each group in whom HR was reduced within the 80 - to 90 -bpm range for at least $30 \mathrm{~min}$. The secondary endpoints included the changes in tissue perfusion reflected in (1) hemodynamic variables obtained by continuous monitoring- $\mathrm{HR}, \mathrm{CO}, \mathrm{CI}$, and SV; systolic, diastolic, and mean blood pressure (SBP, DBP, and MBP, respectively); left ventricular stroke work index (LVSWI); $\mathrm{SvO}_{2}$; right atrial pressure (RAP); pulmonary capillary wedge pressure (PCWP); and urine outputand (2) biological parameters (creatinine clearance and serum lactate).

LVSWI was calculated as LVSWI $=\frac{C I}{H R} \times M B P \times 0.014$ 4 , where 0.0144 represents the conversion factor used to express LVSWI in g.m $/ \mathrm{m}^{2}$.

Safety endpoints, especially arrhythmias, were also monitored by using two-lead Holter monitoring up to $96 \mathrm{~h}$ (from a few minutes before dobutamine until $24 \mathrm{~h}$ after initiation of dobutamine decrease) and myocardial damage by using troponin Ic plasma levels.

The criteria for which the study drug had to be discontinued were bradycardia with HR of not more than $75 \mathrm{bpm}$, onset of post-operative atrial fibrillation (POAF) (except for spontaneously reversible episodes), sustained ventricular tachycardia, and conduction disturbances (atrioventricular or ventricular).

Because the duration of treatment varied among patients, we choose to present the data obtained at five specific time points: (1) at the time of dobutamine introduction because of LCOS (LCOS), (2) at the time of study treatment initiation (H0), (3) two hours after study treatment initiation $(\mathrm{H} 2)$, (4) three hours after study treatment initiation (H3), and (5) immediately prior to study drug discontinuation (last value under treatment).

\section{Statistical analysis}

Continuous values are presented as median and interquartile (25\%-75\%) ranges. Categorical values were compared by using chi-squared tests, and quantitative values were compared by using paired Wilcoxon signed-rank tests based on the non-parametric approach of Hodges and Lehmann for related samples. A $P$ value of less than 0.05 was considered statistically significant.

\section{Results}

\section{Baseline characteristics}

Among 47 patients scheduled for CABG with CPB, 26 developed LCOS and received dobutamine, but only 19 developed sinus tachycardia with an HR of at least $100 \mathrm{bpm}$ and were included in the study: 14 patients were randomly assigned in the ivabradine group and five in the placebo group (study flow chart in Additional file 1: Figure S1).
Demographic pre-operative characteristics collected at the pre-selection visit are presented in Table 1. The two groups were similar regarding systolic heart failure severity, coronary artery disease history, and EuroSCORE. Patients in the ivabradine group tended to be older than patients in the placebo group.

\section{Primary endpoint}

The primary endpoint was reached in 13 (93\%) out of 14 patients of the ivabradine group and in $2(40 \%)$ out of 5 of the placebo group. The introduction of ivabradine was followed by a quick and sustainable $H R$ reduction from $112[105-120]$ to 86 [78-96] bpm $(P<0.001)$ (Fig. 1), compared with placebo group from 112 [104-120] to 104 [89-118] bpm $(P=0.125)$. Intergroup comparison was also significant $(P<0.05)$. The median times to reach the HR target of less than $90 \mathrm{bpm}$ were $1.0 \mathrm{~h}$ [0.5-1.5] for the ivabradine group and $5.7 \mathrm{~h}$ [5.7-5.9] for placebo $(P=0.13)$.

Table 1 Baseline characteristics of patients

\begin{tabular}{|c|c|c|}
\hline & $\begin{array}{l}\text { Ivabradine group } \\
(n=14)\end{array}$ & $\begin{array}{l}\text { Placebo group } \\
(n=5)\end{array}$ \\
\hline Age, years & $61[59 ; 67]$ & $54[53 ; 59]$ \\
\hline Male gender, n (\%) & $11(79)$ & $5(100)$ \\
\hline $\mathrm{BMI}, \mathrm{kg} / \mathrm{m}^{2}$ & $27.5[25.8 ; 28.9]$ & $26.2[25.9 ; 29.7]$ \\
\hline $\mathrm{HR}$, bpm & 73.5 [65.0; 89.0] & $75.0[67.0 ; 77.0]$ \\
\hline $\mathrm{SBP}, \mathrm{mm} \mathrm{Hg}$ & $121[112 ; 130]$ & $115[114 ; 125]$ \\
\hline $\mathrm{DBP}, \mathrm{mm} \mathrm{Hg}$ & $71[66 ; 73]$ & $70[65 ; 75]$ \\
\hline EuroSCORE & $5.5[4.5 ; 6.5]$ & $4.0[2.5 ; 7.5]$ \\
\hline LVEF, n (\%) & $31.5[25.0 ; 38.0]$ & $35.0[27.0 ; 39.0]$ \\
\hline History of MI, n (\%) & $9(64.0)$ & $2(40.0)$ \\
\hline History of PTCA, n (\%) & $5(36.0)$ & $0(0.0)$ \\
\hline History of CABG, n (\%) & $0(0)$ & $0(0)$ \\
\hline \multicolumn{3}{|l|}{ CAD severity, n (\%) } \\
\hline 1 vessel & $0(0)$ & $0(0.0)$ \\
\hline 2 vessels & $1(7.1)$ & $0(0.0)$ \\
\hline 3 or more vessels & $13(92.9)$ & $5(100)$ \\
\hline Dyslipidemia, n (\%) & $11(78.6)$ & $2(40.0)$ \\
\hline Hypertension, n (\%) & $9(64.3)$ & $3(60.0)$ \\
\hline Diabetes, n (\%) & $7(50.0)$ & $2(40.0)$ \\
\hline Heart failure, n (\%) & $7(50.0)$ & $3(60.0)$ \\
\hline Beta-blocker use, n (\%) & $13(92.9)$ & $5(100.0)$ \\
\hline $\mathrm{eGFR}, \mathrm{mL} / \mathrm{min}$ & $82[67 ; 110]$ & $82[76 ; 119]$ \\
\hline
\end{tabular}

Values presented as number (percentage) of patients and median [interquartile range].

Abbreviations: $B M I$ body mass index, $C A B G$ coronary artery bypass graft, $C A D$ coronary artery disease, DBP diastolic blood pressure, eGFR estimated glomerular filtration rate (calculated with Cockcroft-Gault formula), HR heart rate, LVEF left ventricular ejection fraction, $M I$ myocardial infarction, PTCA percutaneous transluminal coronary angioplasty, SBP systolic blood pressure 


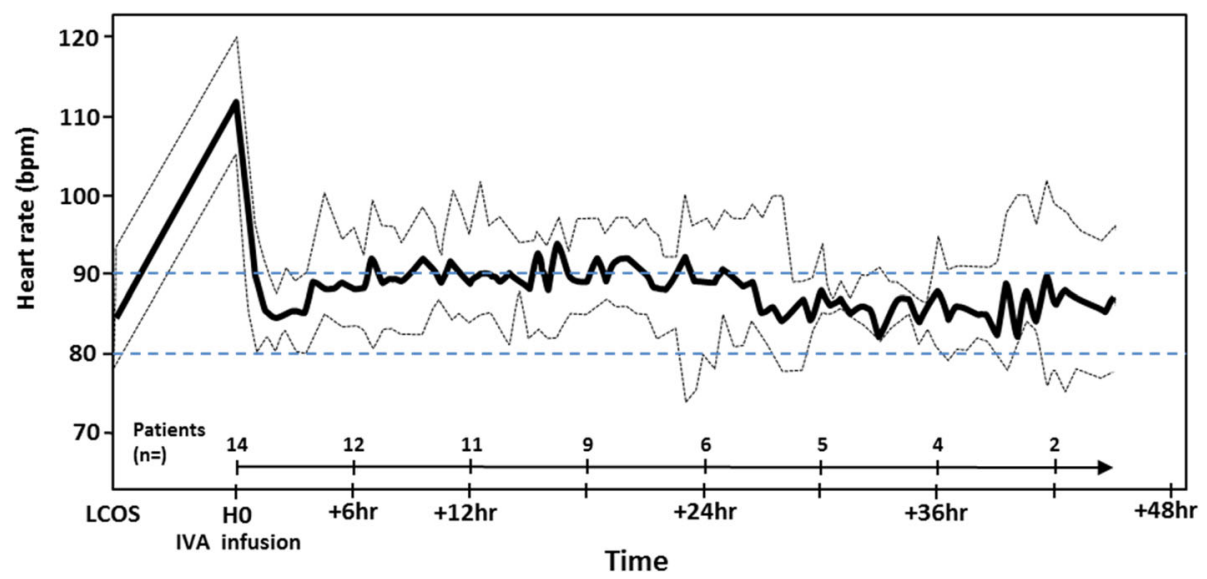

Fig. 1 Heart rate variations in the ivabradine group. The bold line indicates median heart rate value, and the dotted lines delineate the first and third quartiles. Horizontal dashed lines indicate the target range for heart rate. Abbreviations: bpm beats per minute, IVA ivabradine (time of ivabradine initiation), LCOS low cardiac output syndrome (time of dobutamine initiation)

\section{Secondary endpoints}

Results are presented in Table 2. Changes between H0 and treatment cessation were observed in the ivabradine group for SBP $(+19[1-37] \mathrm{mm} \mathrm{Hg}, P<0.05)$; SV $(+23[11-37] \mathrm{mL}, P<0.001)$; CO $(+0.9[0.2-1.7] \mathrm{l} / \mathrm{min}$, $P<0.05)$, CI $\left(+0.6[0.2-0.9] \mathrm{l} / \mathrm{min} / \mathrm{m}^{2}, P<0.05\right)$, and LVSWI $\left(+9.1[2.2-15.6]\right.$ g.m $\left./ \mathrm{m}^{2}, P<0.05\right)$ (Figs. 2 and 3 ). Neither the changes within the placebo group nor the differences between ivabradine and placebo groups reached statistical significance.

The hemodynamic effects of ivabradine were quickly observed: in the ivabradine group, changes between $\mathrm{HO}$ and $\mathrm{H} 2$ were similar to changes between $\mathrm{HO}$ and last value under treatment: SBP $(+9[0-17] \mathrm{mm} \mathrm{Hg}), \mathrm{SV}$ $(+19$ [9-35] mL), CO (+0.6 [-0.1-1.7] l/min), CI (+0.4 $\left.[0-0.8] \mathrm{l} / \mathrm{min} / \mathrm{m}^{2}\right)$, and LVSWI $(+10.6[3.7-17.6])$. Values for these variables at $\mathrm{H} 3$ were comparable to $\mathrm{H} 2$ (Additional file 2: Figure S2).

\section{Effect on concomitant catecholamine administration}

Dobutamine infusion rate was increased in six patients (43\%) with persisting LCOS in the ivabradine group as opposed to none in the placebo group. The resulting hemodynamic variations were similar in the subgroup of patients in whom dobutamine regimen remained unchanged $(n=8)$ (Fig. 3).

Cumulative dose of dobutamine was comparable between the two groups (955 [534-1088] mg in the ivabradine group versus 440 [236-905] $\mathrm{mg}$ in the placebo group, $P=0.18$ ). This difference was due mostly to a difference in treatment duration: $23.7[15.6 ; 38.0]$ hours in the ivabradine group versus $13.8[3.3 ; 15.7]$ hours in the placebo group $(P=0.18)$. In the ivabradine and placebo groups, eight (57\%) and two (40\%) patients were treated with epinephrine, and four (29\%) and one (20\%) were treated with norepinephrine, respectively.

\section{Adverse events}

Five patients $(36 \%)$ developed POAF in the ivabradine group as opposed to none in the placebo group. One episode of bradyarrythmia occurred during the administration of ivabradine, requiring its cessation. The other four episodes occurred after the cessation of ivabradine infusion. In addition, ivabradine was associated with three cases $(21 \%)$ of HR decrease below the threshold of $75 \mathrm{bpm}$, of which two (14\%) required study drug cessation. Finally, one patient presented with several episodes of sustained ventricular tachycardia prior to and after ivabradine administration.

Troponin levels remained stable in both groups (Table 2). One patient in the ivabradine group developed post-operative septic shock and intestinal ischemia five days after study drug discontinuation. The patient died at day 7 following surgery, but this death was not considered related to the study drug. A second patient of the ivabradine group developed lung infection and subsequent septicemia $24 \mathrm{~h}$ following study drug termination. The patient recovered from this infection and ultimately was discharged from the hospital.

\section{Discussion}

In this phase II exploratory multi-center randomized placebo-controlled trial involving patients with LCOS treated with dobutamine after CABG surgery, we observed that i.v. ivabradine infusion was associated with (1) a quick, durable, and significant control of HR in the target range of 80 to $90 \mathrm{bpm}$, (2) a significant increase in SV and SBP, and (3) a higher incidence of POAF and bradycardia. 
Table 2 Hemodynamic variations between treatment initiation and cessation

\begin{tabular}{|c|c|c|c|c|c|c|c|}
\hline & & Ivabradir & $0(n=14)$ & & Placebo & $(n=5)$ & \\
\hline & & Median & [Q1-Q3] & $\overline{P \text { value }^{\dagger}}$ & Median & [Q1-Q3] & $P$ value $^{\dagger}$ \\
\hline $\mathrm{SBP}, \mathrm{mm} \mathrm{Hg}$ & $\mathrm{HO}$ & 110 & [93-118] & $<0.05$ & 111 & [92-128] & ns \\
\hline & Last value & 125 & [114-139] & & 111 & [90-121] & \\
\hline $\mathrm{DBP}, \mathrm{mm} \mathrm{Hg}$ & $\mathrm{HO}$ & 62 & [55-71] & ns & 51 & [50-61] & ns \\
\hline & Last value & 59 & [48-62] & & 55 & [48-67] & \\
\hline MBP, mm Hg & $\mathrm{HO}$ & 78 & [66-83] & ns & 72 & [68-84] & ns \\
\hline & Last value & 80 & [75-82] & & 74 & [60-83] & \\
\hline SV, mL & $\mathrm{HO}$ & 37 & [32-55] & $<0.001$ & 55 & [40-58] & ns \\
\hline & Last value & 60 & [49-79] & & 62 & [40-73] & \\
\hline CO, L.min $\min ^{-1}$ & $\mathrm{HO}$ & 4.7 & [3.6-5.4] & $<0.05$ & 5.4 & [3.3-6.2] & ns \\
\hline & Last value & 5.3 & {$[4.5-6.5]$} & & 5.9 & {$[3.9-7.2]$} & \\
\hline $\mathrm{Cl}$, L.min $\mathrm{min}^{-1} \cdot \mathrm{m}^{-2}$ & $\mathrm{HO}$ & 2.5 & {$[2.0-2.8]$} & $<0.05$ & 2.6 & [1.7-3.1] & ns \\
\hline & Last value & 2.9 & {$[2.4-3.4]$} & & 3.2 & {$[2.4-3.4]$} & \\
\hline LVSWI, g.m.m $\mathrm{m}^{-2}$ & $\mathrm{HO}$ & 20.0 & [13.7-21.7] & $<0.05$ & 18.8 & [13.9-31.9] & ns \\
\hline & Last value & 27.7 & [18.5-32.4] & & 20.5 & [17.4-34.7] & \\
\hline $\mathrm{SvO}_{2}(\%)$ & $\mathrm{HO}$ & 71 & [65-79] & ns & 76 & [75-85] & ns \\
\hline & Last value & 72 & [57-79] & & 81 & [76-84] & \\
\hline PCWP, mm Hg & $\mathrm{HO}$ & 18 & [15-21] & ns & 17 & [16-17] & ns \\
\hline & Last value & 14 & [12-18] & & 13 & [11-18] & \\
\hline RAP, $\mathrm{mm} \mathrm{Hg}$ & $\mathrm{HO}$ & 15 & [10-17] & ns & 14 & [10-14] & ns \\
\hline & Last value & 11 & [11-15] & & 14 & [12-18] & \\
\hline Diuresis, $\mathrm{mL} . \mathrm{kg}^{-1} \cdot \mathrm{h}^{-1}$ & $\mathrm{HO}$ & 1.20 & {$[0.76-3.00]$} & ns & 2.50 & {$[1.42-2.69]$} & ns \\
\hline & Last value & 0.80 & [0.39-1.08] & & 0.60 & {$[0.29-0.82]$} & \\
\hline eGFR, mL.min ${ }^{-1}$ & $\mathrm{HO}$ & 82 & {$[67-110]$} & na & 82 & [76-119] & na \\
\hline & Last value & 76 & {$[62-100]$} & & 62 & [60-67] & \\
\hline Lactate, mmol/L & $\mathrm{HO}$ & 1.9 & {$[1.3-2.8]$} & ns & 2.1 & {$[1.4-2.9]$} & ns \\
\hline & Last value & 1.7 & {$[1.2-2.5]$} & & 1.2 & {$[1.1-1.7]$} & \\
\hline Troponin IC, $\mu \mathrm{g} / \mathrm{L}$ & $\mathrm{HO}$ & 0.90 & {$[0.36-3.00]$} & ns & 2.00 & {$[1.20-5.20]$} & ns \\
\hline & Last value & 2.70 & [0.86-4.33] & & 1.00 & {$[0.89-4.20]$} & \\
\hline
\end{tabular}

${ }^{\dagger}$ Intragroup comparison between $\mathrm{HO}$ and last value under treatment. Abbreviations: $\mathrm{Cl}$ cardiac index, $C O$ cardiac output, $D B P$ diastolic blood pressure, eGFR estimated glomerular filtration rate (calculated with Cockcroft-Gault formula), HO before study treatment initiation, Last value last value under treatment, LVSWI left ventricular stroke work index, MBP mean blood pressure, na not appropriate due to the small sample size (seven patients in the ivabradine group and two patients in the placebo group), ns not significant, $P C W P$ pulmonary capillary wedged pressure, $R A P$ right atrial pressure, SBP systolic blood pressure, SV stroke volume, $\mathrm{SvO}_{2}$ venous blood oxygen saturation

\section{Hemodynamic effects of intravenous ivabradine}

Like its oral counterpart, i.v. ivabradine was found to effectively reduce HR but with a shorter delay of action after treatment onset. This reduction was durable and allowed for a strict control of the HR in a pre-specified target range. In patients with LCOS, dobutamine is commonly used to improve oxygen delivery but induces tachycardia $[25,26]$. It has been argued that most of the improvement in $\mathrm{CO}$ after dobutamine was due to the increase in HR [27]. However, the benefit of improving oxygen delivery may be counterbalanced by the deleterious effect of tachycardia on myocardial oxygen consumption. Indeed, some authors have observed that patients who received dobutamine after cardiac surgery had increased mortality in comparison with propensity-matched patients without dobutamine $[11,12]$. Therefore, there is a sound rationale for controlling $\mathrm{HR}$ in CABG patients with post-operative LCOS treated with dobutamine. In the present study, patients were closely monitored to assess the safety of the dobutamine/ivabradine combination. We observed that the decrease in HR was associated with a concomitant increase in SV and CO. This suggests that the prolonged diastolic time improved left ventricular diastolic filling. The resulting improvement in SV was sufficient to compensate the decrease in $\mathrm{HR}$ and even increased $\mathrm{CO}$. 


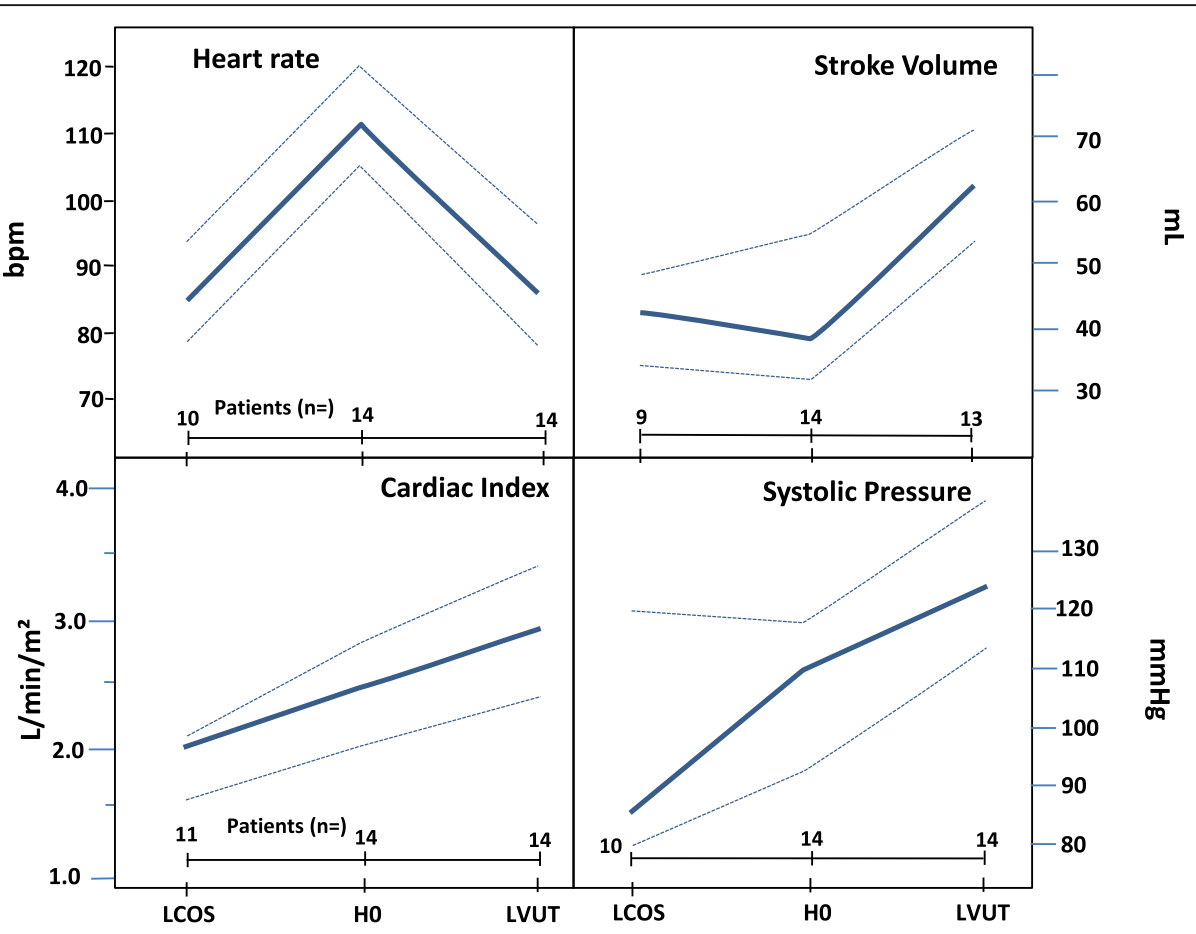

Fig. 2 Hemodynamic variations in the ivabradine group $(n=14)$ between time of dobutamine initiation (LCOS), ivabradine initiation (HO), and cessation. Bold lines represent median values; dotted lines indicate quartiles 1 and 3. Abbreviations: bpm beats per minute, LCOS low cardiac output syndrome, LVUT last value under treatment

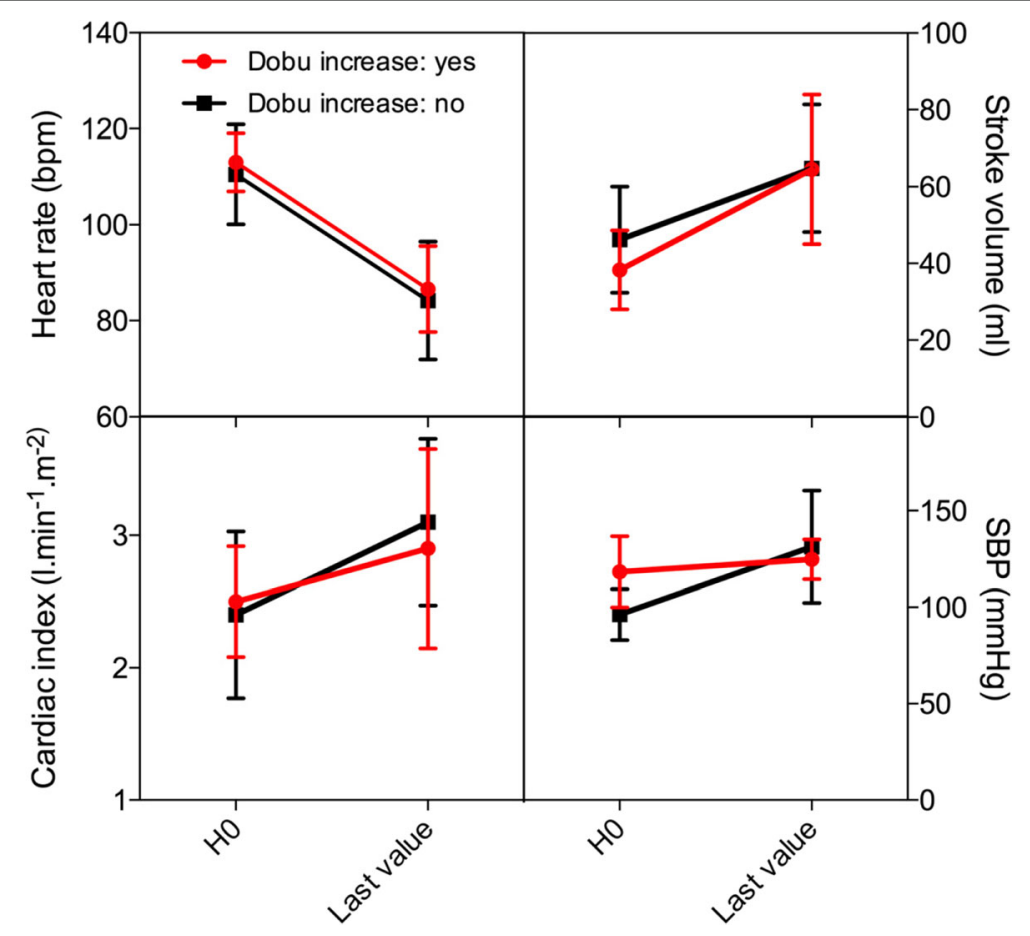

Fig. 3 Comparison of hemodynamic effects of intravenous ivabradine between patients requiring an increase in dobutamine $(n=6)$ and those who did not $(n=8)$. Abbreviations: bpm beats per minute, SBP systolic blood pressure 
These results confirm preliminary animal studies in which dobutamine combined with ivabradine allowed for a simultaneous contractile enhancement and prolongation of diastole, allowing for optimal filling and enhanced $\mathrm{CO}$, in spite of a decrease in HR [22].

Because of the greater SV, SBP increased in the ivabradine group. MBP and DBP remained unaltered, indicating that systemic and left ventricular perfusion pressures were preserved. Overall, LVSWI increased and atrial pressures (RAP and PCWP) tended to decrease, suggesting a beneficial effect on biventricular end-diastolic congestion. The association of increased systemic blood flow, preserved mean arterial pressure, and reduced venous congestion in the systemic and pulmonary veins attests to an improved hemodynamic status. This corroborates the observations that renal function was maintained and that serum lactate did not increase significantly. We can assume that oxygen delivery was adequate and end-organ function was preserved, indicating that LCOS management was effective. These findings suggest that ivabradine did not interfere with a compensatory tachycardia but rather corrected the unwanted dobutamine-induced acceleration in HR.

These results were consistent and confirmed when assessing hemodynamic parameters at $\mathrm{H} 2$ and $\mathrm{H} 3$ after treatment initiation when most ivabradine patients reached target HR, emphasizing the causal role of ivabradine rather than the effect of time (as observed in the placebo group).

Indeed, ivabradine represents one of a few i.v. HR-decreasing agents without negative effects on inotropism, allowing its use in post-operative LCOS. Other existing therapeutic agents include digoxin and magnesium. Intravenous digoxin has the major drawback of presenting dose-dependent toxicity, including potential lethal arrhythmias, hyperkaliemias, and vasoplegic shock. Intravenous magnesium, though less deleterious, has a less significant effect on sinus tachycardia. Beta-blockers are part of the routine treatment for most patients with heart failure (all patients but one in our cohort) but, owing to their adverse effect on contractility and their antagonism with dobutamine, can rarely be administered in the post-operative period. Thus, ivabradine appears as a very promising tool offering an original alternative to control HR, even in patients with severely impaired left ventricular function.

\section{Catecholamine administration in patients receiving ivabradine}

Epinephrine and norepinephrine usage was similar in the two treatment arms. Dobutamine regimen was increased by attending physicians in six ivabradine patients who remained in LCOS. Although we cannot rule out that controlling tachycardia might have reduced $\mathrm{CO}$ in this subgroup, we believe that HR reduction facilitated dobutamine up-titration. The fact that changes in HR, MAP, and SV were similar in the subgroup of patients in whom dobutamine was not increased supports the role of i.v. ivabradine in hemodynamic improvement independently from other concomitant treatments.

\section{Safety issues}

As previously described for oral ivabradine in the SHIFT (Systolic Heart Failure Treatment with the I(f) Inhibitor Ivabradine Trial) [28], the i.v. counterpart was also associated with episodes of arrhythmia and bradycardia. Incident arrhythmias were all supraventricular. Higher dobutamine cumulative dose may be involved in the higher incidence of atrial fibrillation in the ivabradine group, as suggested by the fact that most episodes occurred after ivabradine cessation. These arrhythmias were resolved within a few days of standard treatment. On the other hand, bradycardia, as defined by an HR below 75 bpm, was easily addressed by discontinuing ivabradine. This high threshold for defining "bradycardia" was chosen to avoid leaving patients with LCOS in a low perfusion state. This may have prompted early ivabradine discontinuation in some patients for safety reasons despite the absence of clinical signs of hypoperfusion.

\section{Limitations of the study}

The small number of patients is the main limitation to the validity of our observations. The inclusion criteria of this study were very restrictive in order to include a homogeneous population of patients and to avoid confounding factors. As a consequence, the number of inclusions was small but nevertheless appropriate to reach the primary objective: demonstrating the reduction of $\mathrm{HR}$ in the ivabradine-treated group. Inferential statistics were performed while taking into account the small sample size, allowing us to observe trends in the secondary hemodynamic endpoints. Consequently, adjusted statistical analysis could not be performed to rule out the confounding effects of concomitant catecholamine administration on hemodynamic changes. However, ad-hoc analyses showed that associated catecholamine administration was similar in the two treatment arms. However, even if subgroup comparison among ivabradine patients (a) with dobutamine increase and (b) without dobutamine increase showed similar results in hemodynamic variations, it is not possible to prove that the effect of ivabradine was independent from dobutamine dosage modifications.

Regarding the primary endpoint, we choose to make comparisons between baseline and the time of study drug cessation rather than at a fixed time point. The timing of study drug interruption differed among patients, attesting to the variability in LCOS severity. Indeed, many factors can influence LCOS (i.e., pre-existing 
cardiac dysfunction, $\mathrm{CPB}$ and aortic clamp durations, and quality of myocardial protection during bypass), which cannot be controlled for. Thus, we deliberately choose to make the comparisons between baseline and the time when LCOS was considered over in each patient (dobutamine weaning). This pragmatic approach allowed us to minimize the administration of study drug, which was important from a safety point of view, and to compare patients when they had reached a similar hemodynamic situation. However, it can be noted that changes between $\mathrm{H} 0$ and $\mathrm{H} 2$ (common to all patients) were similar to changes between $\mathrm{HO}$ and the time of study drug cessation. Finally, because investigators were not always available when eligible patients underwent surgery, those who were included in this cohort are not strictly consecutive patients.

\section{Conclusion}

This exploratory study showed that in a specific population of patients, those who had dobutamine-induced tachycardia after elective CABG, the administration of i.v. ivabradine significantly and quickly reduced HR without impairing $\mathrm{CO}$ and arterial blood pressure. Larger studies would be necessary to better assess the overall hemodynamic effects of i.v. ivabradine alone or associated with dobutamine.

\section{Additional files}

Additional file 1: Figure S1. Study flow chart. Abbreviations: HR heart rate, LCOS low cardiac output syndrome. (PPTX 53 kb)

Additional file 2: Figure S2. Hemodynamic variations in the ivabradine group ( $n=14$ ) between time of dobutamine initiation (LCOS), ivabradine initiation ( $\mathrm{H} 0)$, and 2 and $3 \mathrm{~h}$ after ivabradine initiation ( $\mathrm{H} 2$ and $\mathrm{H} 3$ ). Bold lines represent median values, and dotted lines indicate quartiles 1 and 3 . $P$ values are from Wilcoxon signed-rank test. (DOCX $98 \mathrm{~kb}$ )

\section{Abbreviations \\ bpm: Beats per minute; CABG: Coronary artery bypass graft; $\mathrm{Cl}$ : Cardiac index; CO: Cardiac output; CPB: Cardiopulmonary bypass; DBP: Diastolic blood pressure; HR: Heart rate; i.v.: Intravenous; LCOS: Low cardiac output syndrome; LVEF: Left ventricular ejection fraction; LVSWI: Left ventricular stroke work index; MBP: Mean blood pressure; PCWP: Pulmonary capillary wedge pressure; POAF: Post-operative atrial fibrillation; RAP: Right atrial pressure; SBP: Systolic blood pressure; SV: Stroke volume; $\mathrm{SvO}_{2}$ : Venous oxygen saturation of hemoglobin}

\section{Acknowledgements}

We thank Jeremy Grierson for his contribution in reviewing the manuscript and Cécile Henon-Goburdhun for her assistance during the study.

\section{Funding}

Servier laboratories funded this study.

\section{Availability of data and materials}

The data that support the findings of this study are available from Servier laboratories but restrictions apply to the availability of these data, which were used under license for the current study and so are not publicly available. However, data are available from the authors upon reasonable request and with permission of Servier laboratories.

\section{Authors' contributions}

LSN contributed to the study design, interpreted the data, and drafted the manuscript. PS contributed to the study design, included patients, interpreted the data, and supervised the manuscript. JA, DC, KB, and ST included patients and provided critical revision to the manuscript. CA-V and AM contributed to the study design but did not edit the manuscript. BC designed the study, interpreted the data, included patients, and provided critical supervision to the manuscript. All authors read and approved the final manuscript.

\section{Ethics approval and consent to participate}

Ethics approval was given by Comité de Protection des Personnes "lle-deFrance II" led by Pr. C. Herve on April 16, 2010, under research project number 2010-01-02. Consent to participate was given by all patients.

\section{Consent for publication}

All data collected were authorized to be published by participants.

\section{Competing interests}

CA-V and AM are employed by Servier laboratories; they contributed to the study design but did not edit the manuscript. All other authors (LSN, PS, JA, $D C, K B, S T$, and BC) have no conflict of interest regarding Servier laboratories, including consulting fees and shareholdings.

\section{Publisher's Note}

Springer Nature remains neutral with regard to jurisdictional claims in published maps and institutional affiliations.

\section{Author details}

${ }^{1}$ Critical Care Medicine, CMC Ambroise Paré, Neuilly-sur-Seine, France. ${ }^{2}$ Anesthesiology and Critical Care Medicine, Hôpital de la Pitié-Salpétrière, AP-HP, and Université Pierre et Marie Curie, Paris, France. ${ }^{3}$ Anesthesiology and Critical Care Medicine, Institut Mutualiste Monsouris, Paris, France.

${ }^{4}$ Anesthesiology and Critical Care Medicine, Centre Cardiologique du Nord, Saint-Denis, France. ${ }^{5}$ Institut de Recherches Internationales Servier, Suresnes, France. ${ }^{6}$ Anesthesiology and Critical Care Medicine Department, Hôpital Européen Georges Pompidou, AP-HP, and Université Paris

Descartes-Sorbonne Paris Cité, Paris, France.

Received: 15 December 2017 Accepted: 10 July 2018

Published online: 17 August 2018

\section{References}

1. Reynolds HR, Hochman JS. Cardiogenic shock: current concepts and improving outcomes. Circulation. 2008;117:686-97.

2. Rao V, Ivanov J, Weisel RD, Ikonomidis JS, Christakis GT, David TE. Predictors of low cardiac output syndrome after coronary artery bypass. J Thorac Cardiovasc Surg. 1996;112:38-51.

3. Yusuf S, Zucker D, Peduzzi P, Fisher LD, Takaro T, Kennedy JW, et al. Effect of coronary artery bypass graft surgery on survival: overview of 10-year results from randomised trials by the coronary artery bypass graft surgery Trialists collaboration. Lancet. 1994;344:563-70.

4. Kim D-K, Yoo K-J, Hong YS, Chang B-C, Kang M-S. Clinical outcome of urgent coronary artery bypass grafting. J Korean Med Sci. 2007;22:270-6.

5. Algarni KD, Maganti M, Yau TM. Predictors of low cardiac output syndrome after isolated coronary artery bypass surgery: trends over 20 years. Ann Thorac Surg. 2011;92:1678-84.

6. Thiele H, Ohman EM, Desch S, Eitel I, de Waha S. Management of cardiogenic shock. Eur Heart J. 2015;36:1223-30.

7. Teboul JL, Graini L, Boujdaria R, Berton C, Richard C. Cardiac index vs oxygen-derived parameters for rational use of dobutamine in patients with congestive heart failure. Chest. 1993;103:81-5.

8. Link A, Reil JC, Selejan S, Böhm M. Effect of ivabradine in dobutamine induced sinus tachycardia in a case of acute heart failure. Clin Res Cardiol. 2009;98:513-5.

9. Hoke RS, Müller-Werdan U, Lautenschläger C, Werdan K, Ebelt H. Heart rate as an independent risk factor in patients with multiple organ dysfunction: a prospective, observational study. Clin Res Cardiol. 2012;101:139-47.

10. Vanoverschelde JL, Wijns W, Essamri B, Bol A, Robert A, Labar D, et al. Hemodynamic and mechanical determinants of myocardial $\mathrm{O} 2$ consumption in normal human heart: effects of dobutamine. Am J Phys. 1993;265:H1884-92. 
11. Fellahi JL, Parienti JJ, Hanouz JL, Plaud B, Riou B, Ouattara A. Perioperative use of dobutamine in cardiac surgery and adverse cardiac outcome: propensity-adjusted analyses. Anesthesiology. 2008;108:979-87.

12. Nielsen DV, Hansen MK, Johnsen SP, Hansen M, Hindsholm K, Jakobsen CJ. Health outcomes with and without use of inotropic therapy in cardiac surgery: results of a propensity score-matched analysis. Anesthesiology. 2014;120:1098-108.

13. Borer JS. Drug insight: if inhibitors as specific heart-rate-reducing agents. Nat Clin Pract Cardiovasc Med. 2004;1:103-9.

14. Bucchi A, Baruscotti M, Robinson RB, DiFrancesco D. I(f)-dependent modulation of pacemaker rate mediated by CAMP in the presence of ryanodine in rabbit sino-atrial node cells. J Mol Cell Cardiol. 2003;35:905-13.

15. Manz M, Reuter M, Lauck G, Omran H, Jung W. A single intravenous dose of ivabradine, a novel I(f) inhibitor, lowers heart rate but does not depress left ventricular function in patients with left ventricular dysfunction. Cardiology. 2003;100:149-55.

16. Simon L, Ghaleh B, Puybasset L, Giudicelli JF, Berdeaux A. Coronary and hemodynamic effects of S 16257, a new bradycardic agent, in resting and exercising conscious dogs. J Pharmacol Exp Ther. 1995;275:659-66.

17. Tardif JC, O'Meara E, Komajda M, Bohm M, Borer JS, Ford I, et al. Effects of selective heart rate reduction with ivabradine on left ventricular remodelling and function: results from the SHIFT echocardiography substudy. Eur Heart J. 2011;32:2507-15.

18. Reil JC, Tardif JC, Ford I, Lloyd SM, O'Meara E, Komajda M, et al. Selective heart rate reduction with ivabradine unloads the left ventricle in heart failure patients. J Am Coll Cardiol. 2013:62:1977-85.

19. Zwicker C, Becker M, Lepper W, Koch KC, Westenfeld R. Cardiogenic shock due to tachycardiomyopathy after heart transplantation: successful treatment with ivabradine. Cardiology. 2010;116:174-7.

20. Gallet R, Ternacle J, Damy T, Guendouz S, Bremont C, Seemann A, et al. Hemodynamic effects of Ivabradine in addition to dobutamine in patients with severe systolic dysfunction. Int J Cardiol. 2014;176:450-5.

21. Cavusoglu Y, Mert U, Nadir A, Mutlu F, Morrad B, Ulus T. Ivabradine treatment prevents dobutamine-induced increase in heart rate in patients with acute decompensated heart failure. J Cardiovasc Med (Hagerstown). 2015;16:603-9.

22. Bakkehaug JP, Naesheim T, Torgersen Engstad E, Kildal AB, Myrmel T, How OJ. Reversing dobutamine-induced tachycardia using ivabradine increases stroke volume with neutral effect on cardiac energetics in left ventricular post-ischaemia dysfunction. Acta Physiol (Oxf). 2016;218:78-88.

23. Akodad M, Lim P, Roubille F. Does ivabradine balance dobutamine effects in cardiogenic shock? A promising new strategy. Acta Physiol (Oxf). 2016; 218:73-7.

24. De Ferrari GM, Mazzuero A, Agnesina L, Bertoletti A, Lettino M, Campana C, et al. Favourable effects of heart rate reduction with intravenous administration of ivabradine in patients with advanced heart failure. Eur 」 Heart Fail. 2008;10:550-5

25. Butterworth JF, Prielipp RC, Royster RL, Spray BJ, Kon ND, Wallenhaupt SL, et al. Dobutamine increases heart rate more than epinephrine in patients recovering from aortocoronary bypass surgery. J Cardiothorac Vasc Anesth. 1992;6:535-41.

26. Unverzagt S, Wachsmuth L, Hirsch K, Thiele H, Buerke M, Haerting J, et al. Inotropic agents and vasodilator strategies for acute myocardial infarction complicated by cardiogenic shock or low cardiac output syndrome. Cochrane Database Syst Rev. 2014;1:CD009669.

27. Romson JL, Leung JM, Bellows WH, Bronstein M, Keith F, Moores W, et al. Effects of dobutamine on hemodynamics and left ventricular performance after cardiopulmonary bypass in cardiac surgical patients. Anesthesiology. 1999;91:1318-28.

28. Swedberg K, Komajda M, Bohm M, Borer JS, Ford I, Dubost-Brama A, et al. Ivabradine and outcomes in chronic heart failure (SHIFT): a randomised placebo-controlled study. Lancet. 2010;376:875-85.

Ready to submit your research? Choose BMC and benefit from:

- fast, convenient online submission

- thorough peer review by experienced researchers in your field

- rapid publication on acceptance

- support for research data, including large and complex data types

- gold Open Access which fosters wider collaboration and increased citations

- maximum visibility for your research: over $100 \mathrm{M}$ website views per year

At $\mathrm{BMC}$, research is always in progress.

Learn more biomedcentral.com/submissions 